\title{
Prácticas sostenibles de turismo para el tratamiento de aguas y manejo de residuos sólidos en albergues turísticos de Talamanca
}

Sustainable tourism practices for water treatment and solid waste management in tourist lodges in Talamanca

David Arias-Hidalgo ${ }^{1}$, Ronald Aguilar-Álvarez² ${ }^{2}$ Dawn Reinhold ${ }^{3}$

Arias-Hidalgo, D; Aguilar-Álvarez, R; Reinhold, D. Prácticas sostenibles de turismo para el tratamiento de aguas y manejo de residuos sólidos en albergues turísticos de Talamanca. Tecnología en Marcha. Vol. 32, Especial. VIII Encuentro de Investigación y Extensión. Abril 2019.

Pág 89-97.

DOI: https://doi.org/10.18845/tm.v32i6.4231

1 Instituto Tecnológico de Costa Rica. Costa Rica. Correo electrónico: david.arias@itcr.ac.cr

2 Universidad de Costa Rica. Costa Rica. Correo electrónico: ronaldesteban.aguilar@ucr.ac.cr

3 Michigan State University. Estados Unidos. Correo electrónico: reinho17@egr.msu.edu 


\title{
Palabras clave
}

Aguas residuales, residuos sólidos, filtros de agua, educación ambiental, bribris, biogás.

\section{Resumen}

Esta iniciativa de investigación y extensión nació a partir de una ponencia del proyecto titulado Combined water collection, waste treatment, and anaerobic digestion energy provision system for ecotourism in rural Costa Rica. El proyecto fue premiado por la Agencia de Protección Ambiental de los E.E.U.U. en el Sustainable Design Expo del 2015 en Alexandria, Virginia, Estados Unidos. El proyecto tuvo como objetivo integrar tecnologías que promuevan el uso de prácticas sostenibles para resolver problemas de acceso de agua potable y mal manejo de residuos sólidos y líquidos que tienen algunos albergues turísticos en el territorio indígena bribri, Costa Rica. El trabajo se realizó bajo el enfoque de Investigación Acción Participativa (IAP). Los principales resultados fueron: 1) un albergue turístico con un sistema piloto integral de purificación de agua y tratamiento de aguas negras a partir la combinación de tecnologías como filtración, digestión anaeróbica y humedales artificiales, y 2) una estrategia de educación ambiental y sensibilización en albergues turísticos y centros educativos, con un enfoque en manejo de residuos sólidos, seguridad alimentaria y cambio climático.

\section{Keywords}

Wastewater, solid waste, water filters, environmental education, bribris, biogas.

\begin{abstract}
This initiative of research and extension was born from a presentation of the project entitled Combined water collection, waste treatment, and anaerobic digestion energy provision system for ecotourism in rural Costa Rica. The project was awarded by the Environmental Protection Agency of the E.E.U.U. at the Sustainable Design Expo 2015 in Alexandria, Virginia, United States. The objective of the project was to integrate technologies that promotes the use of sustainable practices to solve problems of access to drinking water and poor management of solid and liquid wastes that some tourist shelters have in the Bribri indigenous territory, Costa Rica. The work was carried out under the Participatory Action Research (PAR). The main outcomes of the project were: 1) a tourist lodge with an integrated pilot system of water purification and solid and liquid waste treatment combining technologies such as filtration, anaerobic digestion and constructed wetlands, and 2) an environmental education and awareness-raising strategy in tourist lodges and educational centers, with a focus on solid waste management, food security and climate change.
\end{abstract}

\section{Introducción}

El turismo es una de las principales actividades generadoras de divisas para Costa Rica [10] $y$, en el caso del territorio indígena de Talamanca, hoy el turismo es una realidad, muchas comunidades cuentan con infraestructura y demanda turística, y con más experiencia en las comunidades de Bambú, Shiroles, del distrito Bratsi así como en la cuenca del río Yorkín en el distrito Telire [1]. Con un desarrollo más incipiente se tiene a las comunidades de Amubri, Kachabri y Söki, todas del distrito Telire. Además, cada vez es mayor el interés de los y las 
indígenas en incursionar en la actividad turística y así diversificar la oferta de empleo, para no depender, solamente, de los monocultivos de plátano, banano y cacao [2].

Según Carazo 2004 [5], el turismo que se viene gestando en el territorio indígena está basado en el fomento de su potencial ecológico y cultural. Así lo ha consolidado la comunidad de Yorkín como destino turístico. Por tanto, para garantizar un verdadero desarrollo sostenible del turismo en la región talamanqueña bribri es necesario incentivar ese valor ecológico y cultural de la región que se quiere desarrollar turísticamente y, también, establecer parámetros de medición de los impactos ambientales que la actividad genera en las comunidades receptoras, así como medidas de mitigación para disminuir estos impactos negativos en los ecosistemas y la cultura local.

Respecto de lo anterior, las mayores problemáticas ambientales en el territorio indígena se relacionan con el acceso a agua potable, el aumento en la generación de residuos sólidos y el manejo inadecuado de las aguas residuales, principalmente por el uso de letrinas y ausencia de alcantarillado. Es en ese sentido, este proyecto busca que los albergues turísticos mejoren la calidad de su servicio y reduzcan el impacto ambiental con la implementación de prácticas sostenibles de turismo que integren sistemas de abastecimiento de agua y manejo de residuos líquidos y sólidos.

En 2014, basado en el enfoque de Investigación Acción Participativa (IAP), se formuló un proyecto que integrara tecnologías de bajo impacto al ambiente y que resolviera los problemas de abastecimiento de agua y manejo de residuos líquidos y sólidos en regiones con limitado acceso a agua potable, energía y manejo de residuos. Por tanto, se originó el proyecto titulado Combined water collection, waste treatment, and anaerobic digestion energy provision system for ecotourism in rural Costa Rica, gracias a una alianza estratégica entre Michigan State University (MSU) y el Instituto Tecnológico de Costa Rica (TEC). En abril del 2015, en el marco del National Sustainable Design Expo (NSDE) organizado por la Environmental Protection Agency (EPA) de los E.E.U.U., el proyecto fue reconocido por el impacto a la prosperidad de las personas y protección del planeta, por lo que recibió un financiamiento.

Como proyecto de extensión, el proyecto estuvo adscrito en la Vicerrectoría de Investigación y Extensión (VIE) con el nombre de Implementación de prácticas sostenibles de turismo para el tratamiento de aguas y manejo de residuos sólidos en albergues turísticos de Talamanca, ejecutado del 2016 al 2017, el objetivo general consistió en implementar un sistema integral de purificación de agua, manejo residuos sólidos, y tratamiento de residuos líquidos, en dos albergues turísticos en territorio indígena de Talamanca.

Para lograr el objetivo general se plantearon cinco objetivos específicos:

1. Identificar la composición y cantidad de los residuos sólidos generados en dos albergues turísticos.

2. Diseñar un plan de manejo de residuos sólidos en albergues turísticos.

3. Implementar un sistema de tratamiento de aguas residuales en un albergue turístico.

4. Implementar un sistema de purificación de aguas en al menos 2 albergues turísticos.

5. Sensibilizar a la comunidad y población estudiantil sobre la problemática ambiental con un enfoque de cambio climático. 


\section{Metodología}

El territorio indígena bribri se ubica en la cuenca del Río Sixaola [4]. Dentro de esta cuenca, las comunidades escogidas en el trabajo se encuentran inmersas en el valle de Talamanca en las subcuencas Telire, Yorkín, Urén y Lari. Políticamente, los sitios escogidos pertenecen a los distritos de Telire y Bratsi. Específicamente, se trabajó en las comunidades de Bambú, Yorkín, Amubri y Shuabb, donde se desarrollan los albergues turísticos Ditsöwö ú, Stirblawpa, Koswak, y ACEATA (Asociación Comunitaria de Ecoturismo y Agricultura Orgánica de Telire Talamanca), respectivamente. Para la generación de investigación y extensión, se trabajó bajo el enfoque de IAP [3].

La caracterización de los residuos sólidos se coordinó con el albergue turístico Koswak en Amubri y ACEATA en Shuabb. Se realizaron dos vistas de medición en el primer semestre del 2016 con el propósito de clasificar los residuos sólidos según las siguientes categorías; orgánicos (alimentos), reciclable (vidrio, plástico, papel). Se cuantificó el número de turistas al día de la visita en cada albergue turístico para asociarlo con la cantidad de residuos generados. Por otro lado, se realizaron entrevistas semi-estructuradas a personas que laboran en los albergues para tener insumos y realizar el plan de manejo de los residuos sólidos.

El plan de manejos de residuos sólidos sale a partir de los insumos de la caracterización de cada albergue. Se trabajó bajo el enfoque de diagnóstico rural participativo [6]. Se realizaron tres sesiones de trabajo en cada albergue donde las partes involucradas toman conciencia de la problemática sobre la generación. Posteriormente, se organizaron dos talleres en cada albergue para establecer un plan o estrategia de acción para disminuir y manejar adecuadamente los residuos sólidos.

En Shuabb, con el albergue ACEATA, se diseñó un sistema integral captación de agua, potabilización de agua, manejo de residuos sólidos mediante digestión anaeróbica, y manejo de aguas residuales mediante humedales artificiales. Este sistema fue diseñado por ingenieros y estudiantes de Ingeniería de Biosistemas de MSU. Para la construcción del mismo se contó con el apoyo de estudiantes de MSU, TEC y la Universidad de Costa Rica (UCR).

Se implementaron sistemas de purificación de agua en Shuabb y Amubri, uno a Yorkín, Suretka, Amubri, Bambú y Alto Katsi. Los filtros utilizados libran el agua de patógenos mediante un proceso mecánico de filtrado con microfibras de uso doméstico. El equipo de filtrado se consiguió con una ONG Ilamada AquaClara International. Estos filtros pasan el agua a través de los poros a una velocidad de $60 \mathrm{~L} / \mathrm{h}$. Los tamaños de poro de 0.1 micras permiten el paso de sales y minerales, filtran las bacterias, dejando el agua filtrada al 99.999\% libre de bacterias. Este sistema tiene una vida útil hasta 10 años si los filtros se limpian adecuadamente y de forma regular. Para verificar la eliminación de patógenos en el agua, se realizaron análisis microbiológicos tomando muestras de agua en el sistema de captación de agua y después de los filtros potabilización de AquaClara International. Los análisis se realizaron en campo utilizando petrifilms de 3M para la cuantificación de comunidades de E. coli. Para comprobación de los análisis microbiológicos, se hizo un muestreo certificado con el laboratorio del CEQIATEC, del TEC. Además, se realizaron análisis fisicoquímicos en la fuente de agua para asegurar que las concentraciones de nitrato/nitrito estén por debajo de los límites para consumo de agua potable. Para determinar nitrato/nitrito se utilizaron tiras reactivas WaterWorks.

La sensibilización de la población se abordó de distintas formas. Se trabajó por medio de talleres de educación ambiental con los niños y niñas en las Escuelas del área de influencia del proyecto. Se realizaron actividades de concienciación con la población en general durante los talleres. Se buscó mediante talleres participativos y lúdicos fomentar en la población la cultura del reciclaje, la seguridad alimentaria y la protección del recurso hídrico. A partir de los insumos de los talleres se elaboró un material divulgativo (afiche), que promueve las buenas prácticas 
de turismo sostenible en las comunidades que cuentan con albergues turísticos dicho material fue validado mediante un taller.

\section{Resultados}

Caracterización de los residuos sólidos generados en los albergues turísticos ACEATA y Koswak

El albergue turístico ACEATA se ubica en la comunidad indígena Shuabb, en la subcuenca del río Yorkín, frontera natural entre Costa Rica y Panamá. En dicha comunidad no existe sistema de recolección de residuos sólidos por parte de la Municipalidad de Talamanca. Por tal motivo, la población de Shuabb, en un 100\%, opta por quemar los residuos sólidos no orgánicos. En el caso particular del albergue ACEATA, se registró que la asociación realiza un manejo variado de los residuos sólidos que se generan. El registro del manejo de los residuos sólidos se describe en el cuadro 1.

Cuadro 1. Disposición final de residuos sólidos en el albergue ACEATA

\begin{tabular}{|c|c|c|c|c|c|}
\hline \multirow{2}{*}{\multicolumn{2}{|c|}{ ACEATA }} & \multicolumn{2}{|c|}{ Visita \# 1 con 5 turistas } & \multicolumn{2}{|c|}{ Visita \# 2 con 9 turistas } \\
\hline & & Disposición & $\%$ & Disposición & $\%$ \\
\hline \multirow[t]{3}{*}{$\begin{array}{l}\text { Orgánicos } \\
\text { de la cocina }\end{array}$} & $\begin{array}{c}\text { Cáscaras de frutas } \\
\text { y vegetales }\end{array}$ & Se tira a la montaña & 100 & Se tira a la montaña & 100 \\
\hline & Alimentos & $\begin{array}{c}\text { Alimentar animales } \\
\text { domésticos }\end{array}$ & 100 & $\begin{array}{c}\text { Alimentar animales } \\
\text { domésticos }\end{array}$ & 100 \\
\hline & Aceites o Grasas & Se tira al caño & 100 & Se tira al caño & 100 \\
\hline \multirow[t]{3}{*}{ Botellas } & Vidrio & Se reutiliza & 100 & Se reutiliza & 100 \\
\hline & \multirow{2}{*}{ Plásticas } & Se quema & 60 & Se quema & 80 \\
\hline & & Se reutiliza & 40 & Se reutiliza & 20 \\
\hline \multirow[t]{2}{*}{ Latas } & \multirow[b]{2}{*}{ Aluminio } & Se reutiliza & 20 & Se reutiliza & 30 \\
\hline & & Se quema & 80 & Se quema & 70 \\
\hline \multirow[t]{2}{*}{ Papel } & Normal y cartón & Se quema & 100 & Se quema & 100 \\
\hline & Higiénico & Disposición en letrina & 100 & Disposición en letrina & - \\
\hline
\end{tabular}

El albergue Koswak es un emprendimiento turístico ubicado en Amubri. A pesar de su aislamiento geográfico por el río Telire, Amubri cuenta con una mayor población y más tiendas de abarrotes (pulperías), en comparación con otras comunidades indígenas dentro del territorio indígena bribri, lo que repercute en una mayor generación de residuos. Al igual que en la comunidad de Shuabb, Amubri no cuenta sistema de recolección de residuos sólidos municipal, y su población, en un 90\%, opta por incinerar los residuos sólidos no orgánicos. En general, el manejo de residuos es una problemática significativa en esta comunidad. Se destaca la Escuela de Amubri, en donde existe un módulo ecológico para recolección de residuos valorizables. Lamentablemente, el módulo no está operando. En particular, el albergue de Koswak no cuenta con manejo de residuos, por tanto, no se pudo realizar una caracterización y cuantificación de los residuos generados en el albergue Koswak. 
Diseño de un plan de manejo de residuos sólidos los albergues turísticos de ACEATA y Koswak

El manejo que da ACEATA a los residuos sólidos (ver cuadro 1), promovió que el plan de manejo adecuado de los residuos sólidos se enfocara en siguientes ejes: educación y consumo de alimentos locales. En el caso de educación, se trabajó con dos talleres de sensibilización del impacto de la generación de residuos. Los talleres dieron énfasis a la reutilización de los residuos, puesto que en la comunidad no existen métodos de recolección, ni centros de acopio cercanos. En el caso de consumo de alimentos locales, se identificó que uno de los problemas del albergue de ACEATA es la compra de productos alimenticios que generan residuos. Shuabb es una comunidad con potencial agrícola al contar con espacio para sembrar. Por tanto, se les estimula a fortalecer la seguridad alimentaria en el albergue de manera que sean autosostenibles. Para ello se construyeron dos invernaderos para la producción de hortalizas y leguminosas. También, se capacitó a los miembros de ACEATA en gastronomía local con productos locales, esto con el apoyo del programa Aula Móvil de CONARE.

El plan de mejora en el albergue Koswak tuvo que ser más intenso por los problemas indicados en la sección anterior de caracterización de los residuos sólidos. Básicamente, en este albergue no cuentan con un manejo de residuos. Por ende, el plan de manejo en el albergue Koswak se enfocó los siguientes aspectos: educación y reciclaje. En el caso de educación, se desarrollaron dos talleres de sensibilización del impacto de la generación de residuos. Estos talleres se enfatizaron en la repercusión sobre el ambiente y la salud humana de los desechos sólidos cuando no son tratados adecuadamente. Como punto inicial, se trabajó en establecer un programa de reciclaje. Para el programa de reciclaje, en el albergue Koswak, se construyó un punto ecológico, el cual promoviera la clasificación de residuos sólidos valorizables. La clasificación se hizo basada en los residuos reciclables predominantes en Amubri. La categorización fue plástico, papel y aluminio. Otros residuos especiales, no reciclables, se manejaron con la educación y el apoyo de los turistas. Se capacitó a los encargados del albergue Koswak para explicar a los turistas la necesidad que los mismos turistas llevaran de vuelta los desechos especiales que produjeran, como por ejemplo baterías, bolsas de plástico, aerosoles entre otros. Además, se hizo una rotulación de los basureros y se colocaron rótulos con mensajes y consejos para turistas y los encargados del albergue para sensibilizar sobre la problemática ambiental.

\section{Implementación de un sistema integral de tratamiento de aguas para el albergue ACEATA}

Con los fondos obtenidos en la National Sustainable Design Expo, financiado por EPA se diseñó y construyó un sistema integral de captación y purificación de agua, así como un sistema de tratamiento de residuos sólidos y líquidos el albergue turístico ACEATA. El propósito fundamental fue dotar de agua potable al albergue y tratar las excretas humanas y otros residuos orgánicos, con el fin de evitar la contaminación de las fuentes de agua. Como complemento, se estableció la producción de biogás por medio de un proceso mesofílico de digestión anaeróbica. El biogás se podría utilizar para dar iluminación para el albergue o para la cocción de alimentos. A continuación, se hace una breve descripción del sistema integrado conformado por un sistema de captación y purificación de agua, un biodigestor anaeróbico y un humedal artificial. El sistema de captación de agua es parte del pretratamiento del agua para consumo en el albergue, ya sea para duchas, inodoros, cocina y consumo humano. El agua se toma de una fuente superficial cercana (800 metros de distancia) y se pasa a un filtro remolino de $250 \mathrm{~L}$ (55 galones) para eliminar los sedimentos en el agua. Posteriormente, el agua se almacena en un tanque de 4,500 L (1,000 galones). De este tanque, el agua se conduce a los distintos puntos de consumo. Para asegurar el agua potable para consumo humano, fue 
necesario eliminar patógenos. El sistema de purificación del agua es conformado por filtros de microfibra AquaClara International, ubicados en la cocina y en el sector de los baños. Estos filtros eliminan en más del 99\% los patógenos presentes en el agua. El filtro tiene una vida útil de 10 años, con un mantenimiento de retrolavado todos los días. Pruebas de agua de nitrito, nitrato y patógenos se realizaron antes y después del filtro. Los niveles de concentración de nitrito y nitrato no son un problema en el agua, mientras que los niveles de E. coli. se redujeron de 6 a no detectable, mientras que los coliformes fecales pasaron de 447 a no detectables. El biodigestor anaerobio consta de dos fosas sépticas de polietileno, conectadas en serie, con una capacidad por fosa de $2500 \mathrm{~L}$. Las fosas fueron modificadas para promover un ambiente anaerobio y poder captar el biogás en una bolsa de almacenamiento de plástico de polietileno de alta densidad de 2500 L. Un panel solar de placa plana está conectado a un sistema de intercambiador de calor dentro de las fosas para mantener una temperatura aproximada de 35 ${ }^{\circ} \mathrm{C}$ para asegurar condiciones mesofílicas en el proceso de digestión. El biodigestor anaerobio trata las aguas negras provenientes de los inodoros, y está diseñado para recibir en un futuro excretas de cerdo y desechos de comida. El diseño del digestor anaerobio se calculó para tratar los residuos con el albergue a capacidad máxima de 20 visitantes. Con 20 personas se espera que el digestor anaeróbico reciba $29 \mathrm{~kg} /$ día de excretas humanas, 1,45 kg/día/persona [11]; y 2,5 kg/día de desperdicio de comida, 0,13 kg/persona/día (basado en la observación); una constante de 6,14 kg/día de residuos porcinos, 2 cerdos que excretan 3,07 kg/cerdo/día [9]; y una constante de $5 \mathrm{~kg} /$ día de residuos de cosecha. El biogás a producir tiene el potencial para ser usado como fuente de iluminación o de energía para cocción. Hasta el momento, solo se cuenta con la instalación para uso del biogás para iluminar con linternas los baños del albergue. Las linternas de gas están conectadas con la bolsa de biogás a través de mangueras que conducen el biogás desde la bolsa hasta las linternas.
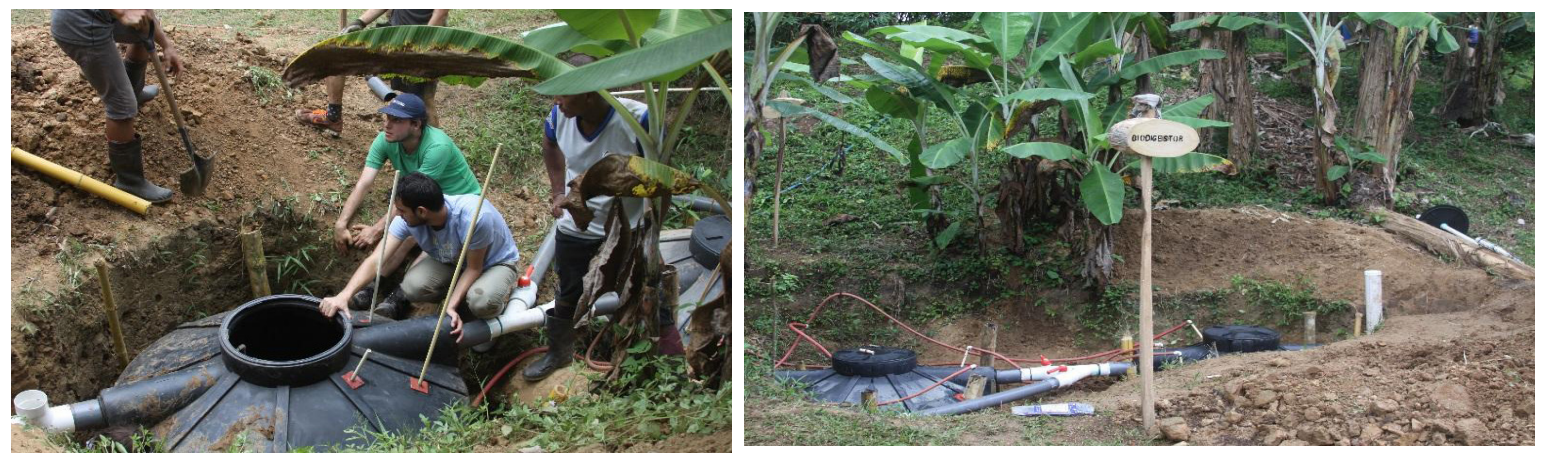

Figura 1. Instalación de biodigestor. A la derecha sistema de biodigestores instalado.

Por último, el humedal artificial, tipo biojardinera, trata las aguas grises provenientes de la cocina, las duchas, los lavatorios y el efluente del digestor anaerobio. El humedal tiene un área aproximadamente $50 \mathrm{~m}^{2}$, con una profundidad de $0.60 \mathrm{~m}$. En la parte inferior del humedal se colocó una capa de piedra bola $(20 \mathrm{~cm})$. Sobre esta capa de piedra se colocó una capa de grava y arena $(40 \mathrm{~cm})$. En la parte superior se han sembrado diferentes plantas, entre ellas; ornamentales como heliconias y comestibles como tomates y chiles. El sistema está dimensionado para reducir las concentraciones de nutrientes antes de verter el efluente al medio ambiente. También, estas aguas pueden ser utilizadas los huertos del albergue. 


\section{Implementación de un sistema de purificación de aguas en ACEATA y Koswak}

Los sistemas de purificación de agua de uso doméstico utilizados son de microfibras plásticas con tecnología $\mathrm{ACl}$ de AguaClara Internacional. La vida útil de estos filtros es de 10 años siempre y cuando se hago un retrolavado diario del filtro. Por tanto, se capacitó a las personas de ACEATA y Koswak en la instalación y el mantenimiento del filtro. Como se muestra en la figura 2 , estos filtros se instalan en baldes de $10 \mathrm{~L}$ de capacidad.

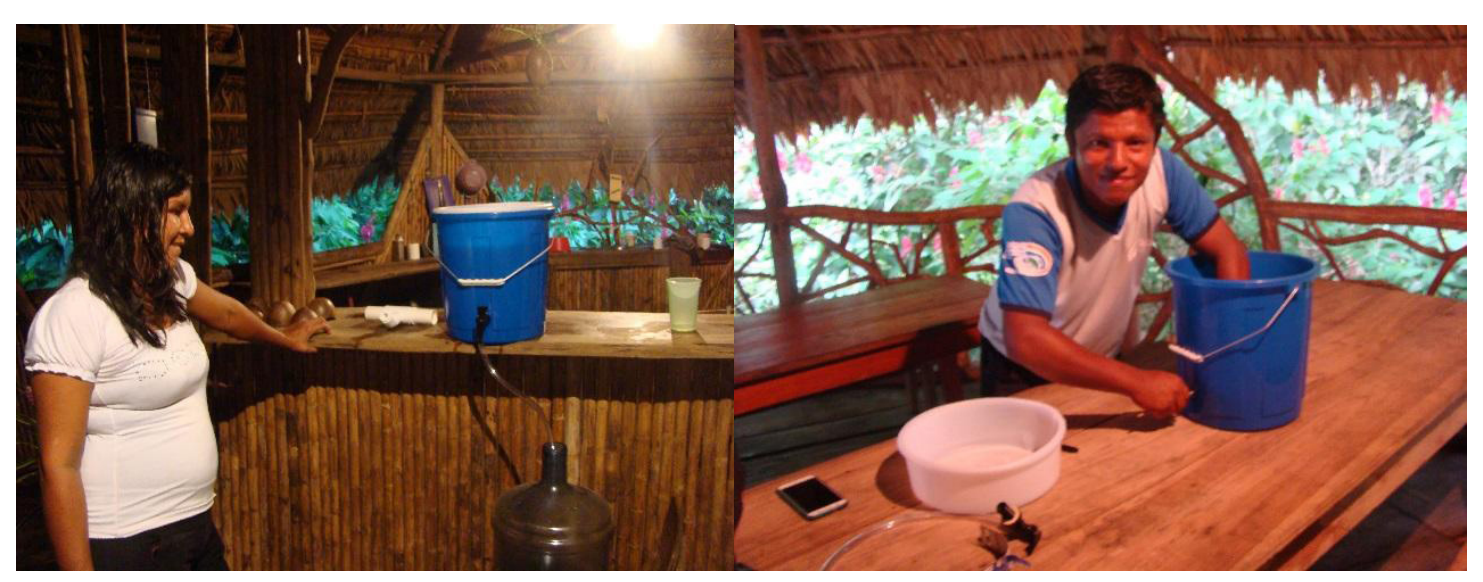

Figura 2. Instalación de filtro doméstico ACl en el albergue Koswak, a la izquierda filtro en funcionamiento.

Debido al éxito de estos filtros por 1) la remoción de patógenos y 2) la facilidad de instalación y mantenimiento, se decidió instalar más filtros en cuatro albergues turísticos, dos escuelas y una finca agro-turística. Para asegurar la no presencia de bacterias (coliformes fecales y E. coli.) en el agua filtrada, se realizaron análisis de microbiológicos con placas Petrifilm de 3M. También, se realizaron pruebas certificadas con el Centro de investigación y de Servicios Químicos y Microbiológicos (CEQIATEC). Las pruebas certificadas sólo se realizaron en Amubri, albergue Koswak, y Shuabb, albergue ACEATA (cuadro 2).

Cuadro 2. Resultados de análisis de agua antes y después del filtro 1 en el Albergue ACEATA. Shuabb. Talamanca.

\begin{tabular}{|c|c|c|c|c|}
\hline \multirow{2}{*}{ Fecha muestreo } & \multicolumn{2}{|c|}{ Antes del filtro } & \multicolumn{2}{c|}{ Después del filtro } \\
\cline { 2 - 5 } & $\begin{array}{c}\text { Coliformes fecales } \\
\text { NMP/100ml }\end{array}$ & $\begin{array}{c}\text { Escherichia coli } \\
\text { NMP/100ml }\end{array}$ & $\begin{array}{c}\text { Coliformes fecales } \\
\text { NMP/100ml }\end{array}$ & $\begin{array}{c}\text { Escherichia coli } \\
\text { NMP/100ml }\end{array}$ \\
\hline $12-05-16$ & 27 & 27 & No detectable & No detectable \\
\hline $15-05-17$ & 33 & No detectable & No detectable & No detectable \\
\hline $29-09-17$ & No detectable & No detectable & No detectable & No detectable \\
\hline
\end{tabular}

Fuente: Tomado de los informes de resultados de análisis por CEQIATEC.

Sensibilizar a la comunidad y población estudiantil sobre la problemática ambiental con un enfoque de cambio climático

Se han realizado 16 talleres dirigidos a niños y niñas de Escuelas del área de influencia del proyecto. Estos talleres se han ejecutado con el apoyo de estudiantes de diferentes carreras del TEC. Los talleres se han enfocado en sensibilizar a la población joven la importancia de: 
1) proteger el recurso hídrico, 2) dar un manejo adecuado a los residuos sólidos y 3) fomentar la seguridad alimentaria. En lo referente a los talleres de sensibilización ambiental dirigidos a la población, se realizaron 10 en diferentes comunidades del área de influencia del proyecto. Las comunidades beneficiarias fueron Amubri, Bambú, Suretka, Alto Katsi, Shuabb y Yorkín. En estos talleres se contó con la participación activa de estudiantes de diferentes carreras del TEC, MSU y UCR.

\section{Discusión}

Las características y cantidades de los residuos generados en ACEATA y Koswak son similares. En ambos casos sobresale el mal manejo de residuos de origen plástico, aluminio y papel. En general, estos residuos eran incinerados en ambos albergues. En contraposición, el manejo de los residuos orgánicos no es un problema para los albergues turísticos, ya que se observó un adecuado aprovechamiento. Por ejemplo, los residuos orgánicos se colectan y dan como alimento para animales domésticos.

El plan de manejo de residuos sólidos radica en la educación, la cual se convierte en la principal herramienta para concienciar a la población sobre el daño ambiental que genera la práctica de quema de residuos. Tanto en ACEATA como en Koswak se recalcó en la importancia de una selección de residuos, principalmente los reciclables. El problema es la acumulación de estos materiales reciclables en la zona, por lo que se trabaja en conjunto con el turismo para que ellos mismos se hagan responsables de sus desechos.

La implementación de un sistema integrado de tratamiento de agua en ACEATA ha sido acogida de gran manera por los asociados de este albergue turístico. El sistema cubre las necesidades de 1) agua para consumo humano, incluso apta para ingerir, 2) manejo de residuos sólidos, con producción de biogás, y 3) manejo de residuos líquidos. Este concepto del manejo de los residuos es el primero en la zona y puede ser replicado a otros sitios en la zona. En general, todo el sistema ha funcionado.

Los sistemas de purificación de agua han sido exitosos en Amubri, Bambú, Shuabb, Suretka y Alto Katsi, por 1) la eficiencia en la remoción de patógenos y 2) la facilidad de instalación y mantenimiento de los filtros. Las pruebas realizadas con las placas Petrifilm de 3M muestran la ausencia de bacterias, exceptuando el filtro instalado en Koswak a Amubri, que mostró inconsistencia en una prueba Petrifilm y en dos pruebas de laboratorio realizadas en CEQIATEC. Uno de los beneficios más importantes es el ahorro económico por no comprar agua potable. Por ejemplo, el albergue de Koswak reportaba la compra de hasta 3 bidones de agua para suplir la máxima de capacidad de hospedaje, los cuales no volvieron a ser necesarios.

Sensibilizar con educación. La educación ambiental debe fomentar la generación de conciencia, valores y comportamientos que favorezcan la toma de decisiones de la población [7]. La actividad lúdica va de la mano con el aprendizaje y propicia el desarrollo de las aptitudes, las relaciones y el sentido del humor en las personas [8]. La escogencia de las temáticas de los talleres se hizo mediante consenso con los responsables de los centros educativos en territorio indígena (maestros y directores). Los talleres propiciaron espacios lúdicos para el aprendizaje de los participantes, mediante obras de teatro, jornadas de reforestación, sociogramas, títeres, manualidades, etc. Entre las técnicas lúdicas, las de mayor aceptación fueron los títeres y las obras de teatro, a lo que cabe agregar que un aspecto significativo fue integrar elementos de la cosmovisión bribri, así como el idioma y la tradición oral. 


\section{Conclusiones}

La educación ambiental es imprescindible para generar cambios en las inadecuadas prácticas ambientales y generación de residuos sólidos, motivo por el que los talleres de educación ambiental se enfocaron en su mayoría en seguridad alimentaria, pues el proceso de transculturación y el cambio a una economía de mercado son problemáticas que se asocian con la generación de residuos sólidos en el territorio indígena. Esta educación también repercute positivamente en la implementación y seguimiento de planes de manejo de estos residuos en conjunto con los visitantes.

La integración de tecnología fue importante para dar un manejo integral de los recursos y residuos en el albergue de ACEATA. Principalmente, el sistema de tratamiento ha sido efectivo en cuanto al tratamiento de las aguas negras y grises en el humedal, a lo que se aúna que los cultivos como el chile y tomate silvestre crecen bien en este ecosistema artificial; sin embargo, la generación de biogás en el sistema aún es mínima. Se valorará agregar al sistema otro sustrato, como excreta de cerdo o frutas altas en fructosa para aumentar la producción de biogás.

Los filtros de purificación de agua han sido bien aceptados por los beneficiarios, su fácil mantenimiento y uso ha facilitado la efectividad de los mismos, lo cual se evidencia en las pruebas de laboratorio que demuestran la ausencia de E. coli. y coliformes fecales en las muestras tomadas después de aplicado el filtro.

El proyecto ha permitido generar un espacio multicultural, ideal tanto para el entrenamiento de estudiantes de ingeniería, como otras carreras del TEC, UCR y MSU. Solucionando problemas desde la práctica y propiciando el trabajo en equipo e interdisciplinario dirigido a una población beneficiaria en alta vulnerabilidad social. Lo cual refuerza la formación humanística de los estudiantes.

Gracias al establecimiento del sistema integral de tratamiento de aguas del albergue ACEATA en Shuabb, este centro turístico puede promocionarse y posicionarse como un proyecto turístico ecológicamente sostenible que se ocupa de los desechos líquidos de una manera responsable con ambiente y de una forma innovadora. Además de promover el desarrollo económico local por el aumento en la visitación turística.

\section{Recomendaciones}

Estudiar la viabilidad del proyecto para una segunda etapa, en el corto plazo, dar énfasis al uso de los filtros caseros, verificar su funcionalidad a unos 5 años para validar su vida útil y el mantenimiento en los albergues. Además, se recomienda, en el próximo proyecto ampliar el trabajo con más escuelas del territorio indígena y comunidades más aisladas donde el acceso al agua potable es una problemática latente.

Se recomienda establecer alianzas estratégicas con entes del Gobierno Central como Acueductos y Alcantarillados, Ministerio de Salud, Caja Costarricense del Seguro Social y organizaciones sin fines de lucro como AquaClara Internacional para proveer por medio de donaciones los filtros $\mathrm{ACl}$ caseros a familias indígenas.

Se deben hacer pruebas microbiológicas en el afluente del humedal para confirmar la ausencia de patógenos en el agua, si el agua no presenta patógenos se podría utilizar el agua para riego de plantas comestibles. 


\section{Agradecimientos}

Un agradecimiento a la United States Environmental Protection Agency, Vicerrectoría de Investigación y Extensión, y a la Oficina de Equidad de Género ambas del Instituto Tecnológico de Costa Rica por propiciar este proyecto de extensión dirigido a la comunidad indígena de Talamanca.

\section{Referencias}

[1] D. Arias, Caracterización de Albergues Turísticos y Percepciones sobre el Turismo en el territorio Indígena Bribri Talamanqueño, Trama, vol. 5, pp. 24-32, 2016 [En línea]. Disponible en: http://revistas.tec.ac.cr/index. php/trama/article/view/2615/2375

[2] D. Arias y J. Solano, Programa de Capacitación para Guías Turísticos Locales en Territorio Indígena de Talamanca, trabajo de fin de grado, ITCR, Costa Rica, 2009.

[3] F. Balcazar, "Investigación Acción Participativa (IAP): Aspectos Conceptuales y Dificultades de Implementación", Fundamentos en Humanidades, vol. IV, no. 7-8, pp. 59-77, 2003.

[4] S. Candela, "Convergencias y divergencias entre organizaciones indígenas y externas respecto al uso y la conservación de recursos naturales en los territorios indígenas de la Alta Talamanca, Costa Rica", Tesis Mag. Sc. Turrialba, CATIE. Costa Rica, 2007.

[5] F. Carazo, "Estudio de factibilidad fomento al turismo cultural Río Yorkín", 2004 [En línea]. Disponible en http:// www.parksinperil.org/files/estudio_turismo_yorkin.pdf

[6] M. Expósito, "Diagnóstico Rural Participativo Una guía práctica". ISBN : 99934-24-10-2 Centro Cultural Poveda, 2003.

[7] J. Goikoetxea, "Actividades y recursos para la educación ambiental en educación infantil", 2014 [En línea]. Disponible en http://biblioteca.unirioja.es/tfe_e/TFE000690.pdf

[8] T. Gómez, O. Rodríguez y S. Molano, "La actividad lúdica como estrategia pedagógica para fortalecer el aprendizaje de los niños de la Institución Educativa Niño Jesús de Praga". Trabajo de grado para optar al título de Licenciado en Pedagogía Infantil, Instituto de Educación a Distancia, Tolima, 2015 [En línea]. Disponible en http://repository.ut.edu.co/bitstream/001/1657/1/APROBADO\%20TATIANA\%20G\%C3\%93MEZ\%20 RODR\%C3\%8DGUEZ.pdf

[9] D.W. Hamilton, W. G. Luce, A.D. Heald, "Production and Characteristics of Swine Manure," Oklahoma State University (OSU), 1997 [Online]. Available: http://agrienvarchive.ca/bioenergy/download/F-1735 swine man char OK.pdf

[10] L. Pratt, "Logros y Retos del Turismo", 2002 [En línea]. Disponible en: https://www.incae.edu/ES/clacds/publicaciones/pdf/cen608.pdf

[11] UNEP, "Environmentally sound technologies in wastewater treatment for the implementation of the UNEP Global Programme of Action (GPA). Guidance on municipal wastewater," Osaka/Shiga: UNEP Division of Technology, Industry and Economics, International Environmental Technology Center, 2001. 